\title{
How Integrating Indigenous Perspectives into the Classroom Affects Students Attitudes Towards Indigenous Peoples
}

\author{
Tiffany Prete \\ University of Alberta \\ tbevans@ualberta.ca
}

\begin{abstract}
This paper explores the methods employed by Alberta Education to teach Alberta students about the Indigenous ${ }^{1}$ Peoples of Canada. Currently, Alberta Education has two approaches, which are: 1) the integration of the First Nations, Metis, and Inuit Policy Framework (FNMI), which is a framework that is a means to educate all Albertans on the history of Aboriginal Peoples, and 2) an optional Aboriginal Studies coursework. An urban high school participated in this research study, which was under the call for the integration of the FNMI policy framework and also offered Aboriginal Studies 10. I used a Blackfoot theoretical framework, grounded in an Indigenous research methodology, alongside principles of the Beadworking paradigm to conduct the research. I employed a survey that was quantitative in nature to determine students' attitudes towards the Indigenous Peoples of Canada. I was interested in identifying whether taking Aboriginal Studies 10 made a difference in the participants' views of Indigenous Peoples. I used principal-component factor analysis and multivariate analysis of variance (MANOVA) to analyze the data. The results from the MANOVA analysis indicate that the Aboriginal Studies 10 class plays a role in students' perceptions of Indigenous Peoples specifically. These results indicate that students who participated in the Aboriginal Studies 10 course had a more positive view of Indigenous Peoples than students who did not participate in Aboriginal Studies 10.
\end{abstract}

\section{Introduction}

I still remember the contemptuous looks and snide remarks I received while attending my piano lessons at nine years of age. My piano teacher's father was not very keen to have an Indigenous child (I am a member of the Kainiwa ${ }^{2}$ Nation, of the Siksikaitsitapi ${ }^{3}$ ) in his home, and he was not at all bashful in vocalizing his disdain for me. There were times when he would try to literally shove me out of his home. His treatment of me was not unusual, and I had begun to grow accustom to being treated in such a manner. I was, however, confused as to why people treated me in such a fashion. As I grew older, I began to see the profound disparities in the ways in which Indigenous Peoples were, and are, treated by society. But it really was not until I entered graduate studies that I would learn from where this animosity arose, and how deeply it has been entrenched into our society.

\footnotetext{
${ }^{1}$ Throughout this paper, I will interchangeably use the terms Indigenous, First Nations and Aboriginal where most appropriate.

${ }^{2}$ Kainiwa translated into English means the Blood Tribe.

${ }^{3}$ Siksikaitsitapi translated into English means Blackfoot Confederacy. Journal of Contemporary Issues in Education, 2020, 15(2), pp. 120-134. (c) Author(s), Creative Commons Attribution 4.0 (CC BY 4.0) licence. http://ejournals.library.ualberta.ca/index.php/JCIE doi 10.20355/jcie29387 
As a member of the Kainaiwa Nation, located in Alberta, Canada, I choose to focus this paper specifically on the province of Alberta, as well as Canada at large. Our societal structure has been shaped by the numerous acts and agreements made between various groups of Indigenous Peoples and the colonial powers to come to Turtle Island. The Royal Proclamation of 1763 would be amongst the first acts to legislate for and on behalf of Indigenous Peoples without their input or consent (Royal Proclamation, 1763, p. 3). Slowly, Indigenous Peoples' power of sovereignty would be eroded with each passing act, until we arrived at one of the most oppressive pieces of legislation, An Act to Amend and Consolidate the Laws Respecting Indians (Indian Act, 1876). More commonly referred to as the Indian Act, this act legislated every aspect of Indigenous Peoples' lives. Amongst its most horrific policies was the forced mandatory attendance of Indigenous children in colonial education systems, including the Indian Residential Schools (Indian Act, 1894; Indian Act, 1920).

The Indian Act also set a precedent for the manner in which Indigenous Peoples would be thought about and treated. The intention behind the Act was to "civilize" the Indigenous Peoples and to assimilate them into the wider Euro-Western population (Gradual Civilization Act, 1857; Indian Act, 1876). In recent years, much work has been done to bring to light the truth of what has happened to the Indigenous Peoples of Canada, which is Canada's history. Most influential has been the work of the Truth and Reconciliation Commission (TRC) of Canada. Senator Murray Sinclair, the Chair of the TRC, taught:

Seven generations of children went through the residential schools, and each of those children who were educated were told that their lives were not as good as the lives of the non-Aboriginal people of this country. They were told that their languages their cultures were irrelevant. They were told that their People and their ancestors were heathens and pagans and uncivilized, and needed to give up their way of life, that they had to come to a different way of living. At the same time that that was going on, non-Aboriginal children in the non-Aboriginal school systems of this country were also being told the same thing about Aboriginal people. So as a result, many generations of children, including you and your parents have been raised to think about things in a different way, in a wrong way, and in a way that is a negative when it comes to Aboriginal People. We need to change that. It was the educational system that has contributed to this problem in this country. And it is the educational system we believe that is going to help us to get away from this. We need to look at the way we educate children. (National Centre for Truth and Reconciliation, 2019)

As an Indigenous scholar, I use the principles of the Beadworking research paradigm and an Indigenous research methodology to conduct research that could potentially be beneficial to my People. I decided to explore how education can be used to help foster positive attitudes towards the Indigenous Peoples of Canada. Focusing on Alberta Education, I designed a quantitative research project that sought to answer the following research question from the students' 
perspectives: "How does engaging with either the First Nations, Metis, and Inuit policy framework or Aboriginal Studies 10 course work affect students' attitudes towards Indigenous Peoples?" This paper is part of a larger study that I have conducted with regards to Alberta Education's First Nations, Metis and Inuit Policy Framework (FNMIPF; Alberta Education, 2002).

Presently at the secondary level, Alberta Education offers two approaches for learning about the Indigenous Peoples of Canada: (a) Alberta Education's FNMIPF that integrates Indigenous perspectives into the kindergarten to grade 12 core curriculum (Alberta Education, 2002), and (b) the optional Aboriginal Studies 10 coursework. Which of these educational practices (being educated with the FNMIPF or Aboriginal Studies 10) makes the most significant difference to students' attitudes towards Indigenous Peoples? Aboriginal Studies 10 refers to education on Canadian Indigenous' history, knowledge systems, or cultures.

The research took place in the Treaty 7 area, in one of the only high schools offering Aboriginal Studies 10 (Alberta Education personnel, personal communication, March 13, 2010). The school had a student enrolment of between 300 and 500 students; I have masked the number for confidentiality purposes. Nearly one third of the student population was Indigenous. Permission to conduct the research was granted from the school district's superintendent and school principal. The date and time that the survey was administered was chosen by the school principal. Participants ranged from Grades 10 through 12; all students aged 15 and older were asked to participate. The school notified the students about the research study prior to the administration of the survey. Participants received an invitation to participate in the research study, which included an information letter, consent form, and the survey questionnaire. The Research Ethics Board at the University of Alberta approved the participant group to include students aged 15 and older as mature adults, who could sign their own consent forms. Completion of these surveys was entirely voluntary. Anonymization of students' identities was used through numeric identification codes. I invited a total of 350 students to participate in the survey; 232 completed the surveys, a $66 \%$ return rate. As there are no other known empirical studies having explored this phenomenon from the students' perspectives, it is impossible to compare the findings from this study with those of other studies.

This research has the potential to influence political and social structures by challenging the societal norms that have resulted from colonization and that have remained intact in the public school system. This research will also contribute to the still limited literature on Indigenous education in Canada. Furthermore, researchers have not yet addressed the significance of the effects of learning about Canadian Indigenous histories on students' perspectives and understanding. Mandatory learning on Indigenous history for all students can be a critical factor in the success of Indigenous students in the Canadian public education school systems.

\section{Background}

The arrival of the Europeans in the Americas forever altered the existence of Indigenous Peoples. Colonization introduced and solidified a system of white supremacy that would greatly affect the manner in which Indigenous Peoples would be treated (Bonds \& Inwood, 2016; Fredrickson, Journal of Contemporary Issues in Education, 2020, 15(2), pp. 120-134. 
1982; Rabaka, 2007; Yellow Bird, 2004). Additionally, colonization brought not only many economic, political, and social changes to the Indigenous Peoples, but also a change in the way that Indigenous Peoples were educated. Missionaries from the Roman Catholic, Anglican, Methodist, United, and Presbyterian churches began opening mission schools in the 1600s amongst the Indigenous Peoples (Canadian Encyclopedia Online, 2009; Carney, 1995). By the mid-1800s, Canada had become a country and began writing legislation, such as the British North American Act (1867) and the Indian Act (1876), that would dictate policies surrounding Indigenous Peoples' education. In the Amendment to the Indian Act (1884), it became compulsory for Indigenous children to attend either a day, boarding, residential, or industrial school operated by one of the previously mentioned denominations. The Amendment to the Indian Act (1920) made it mandatory that all Indigenous children had to attend a residential school. The Canadian Government, enacting white supremacy, would continue to change legislation multiple times, using the law to make it criminal for Indigenous Peoples to practice and live their traditional ways of life (Indian Act, 1884, Indian Act, 1895, Indian Act, 1914, Indian Act, 1920, Indian Act, 1927). The main objective of Indigenous education during this era was an assimilative one, where schools would "kill the Indian in him, and save the man" (Aboriginal Affairs and Northern Development, 2011; Bagot, 1842; Bryce, 1907; Carney, 1995; Kirkness, 1999; Ryerson, 1898: Pratt, 1973, p. 260).

Indigenous Peoples' education during this time had been a federal responsibility. That all changed when the Amendment to the Indian Act (1985) resulted in a provincial agreement to hold schools accountable for the education of Indigenous students at the provincial level. In 1987, Alberta Education came out with the Native Education Project (NEP), which was the province's first policy framework attempt at addressing its Indigenous students' needs. It also intended to develop for all students a curriculum that would depict a positive view of Indigenous Peoples and encourage Indigenous parents to become part of their children's education (Scheffel, 2000).

Alberta Education (1987) created four policy objectives to meet the needs of Indigenous students, and the NEP (Alberta Education, 1987) developed multiple projects to accomplish these goals. However, once the government met these goals, it stopped developing resources and setting new goals. The majority of the curriculum development and implementation occurred during the late 1980s and early 1990s. The project initiatives were located only in certain schools, and the implementation of the NEP curriculum was only encouraged and not mandatory in school districts (Alberta Education, 1987). The Treaty 7 First Nations Education System (T7FNES) published a review of the NEP and shared three categories of concerns that they had, which were: 1) early childhood services to grade 12 issues; 2) post-secondary information from community meetings; and 3) strengthening partnerships between First Nations school jurisdictions, post-secondary institutions, apprenticeship providers, vocational schools, industry and government (T7FNES, 2000). Additionally, T7NFES maked 13 recommendations for how Alberta Education could improve First Nations learner success in early childhood studies to grade 12 (T7FNES, 2000). The Alberta Education (1987) policy statement was no longer applicable to Indigenous students; thus, NEP would come to an end and Alberta Education 
would begin to develop a new policy framework to better meet the needs of Aboriginal students today.

Next Alberta Education (2002) created the First Nations Metis Inuit policy framework (FNMI), basing it on the recommendations from the T7FNES review (Alberta Education, 2002). To date, Alberta Education has only published two FNMI progress reports (Alberta Education, 2004, 2008). Two distinct differences exist between the NEP (Alberta Education, 1987) and the FNMI Policy Framework: (a) the integration of "First Nations, Métis, and Inuit governance, history, treaty and Aboriginal rights, lands, cultures and languages" (Alberta Education, 2002, p. 10) in all core classes from kindergarten to Grade 12, and (b) the creation of culture classes, namely Aboriginal Studies 10-20-30.

Instead of focusing on the seven objectives mandated for all core classes, each Aboriginal Studies class focused on four separate themes, which I discuss to highlight the different approaches to teaching about Aboriginal Peoples in Alberta schools. The four themes of Aboriginal Studies 10 are: (a) origin and settlement patterns, (b) Aboriginal worldviews, (c) political and economic organization, and (d) Aboriginal symbolism and expression. The four themes of Aboriginal Studies 20 focus on the Métis: (a) conflict and cultural change, (b) treaties and cultural change, (c) legislation, policies, and cultural change, and (d) schooling and cultural change. The four themes of Aboriginal Studies 30 include: (a) Aboriginal rights and selfgovernment, (b) Aboriginal land claims, (c) Aboriginal Peoples in Canadian society, and (d) Aboriginal world issues.

The religious denominations and the Canadian Government, during the mission and residential school eras, held an attitude towards Indigenous Peoples identified as cultural genocide (Amir, 2018; Mako, 2012; Reyhner \& Singh, 2010). Canadian schools today have a chance to rectify this long held colonial assumption of white supremacy that schools have enacted, and to help put an end to the cultural genocide of the Indigenous Peoples of Canada. Fostering positive attitudes towards Indigenous peoples may rectify this issue. My Blood Tribe People reside within the Province of Alberta, thus, this paper will focus on Alberta Education's FNMI policy framework. However, other provincial and territorial governments across Canada have implemented similar policy frameworks to that of Alberta Education's. Therefore, this paper can be of value to all education systems found in Canada.

\section{Theoretical Framework and Methodology}

In this study, I used Beadworking (Prete, 2019) as a theoretical framework and research paradigm that uses Indigenous Peoples' bead work to guide the research process, while being grounded from within a Blackfoot worldview. The Beadworking paradigm comprises three principles, which are beadworking as an act of: (a) resistance, (b) knowledge transmission, and (c) resiliency. Additionally, Beadworking is applied to an Indigenous research methodology informed by Martin (2002) and Weber-Pillwax (2001) advocating for the privileging of Indigenous voice, the interconnectedness of all living things, and consciousness of the impact 
motives and intentions have on individuals and communities. I will give a brief overview of the three principles of Beadwork and how they apply to an Indigenous research methodology.

An Act of Resistance means to resist oppression by returning the colonial gaze (Walter, 2005), by using Indigenous ways of knowing, being, and doing to advance an Indigenous agenda. An Act of Knowledge Transmission means to engage, embody, and transmit or transfer my own People's ways of knowing, being, and doing. I will accomplish this through living the natural laws of the Blackfoot, which are: reciprocity, interconnectedness, kindness/generosity, respect, balance/harmony, and sharing/giving (Bastien, 2004). I heavily rely upon the natural laws of interconnectedness and balance, which speak to the Blackfoot Peoples' holistic way of existing in the world. An Act of Resiliency refers to our adaptability as Indigenous Peoples. As Indigenous research is relatively new to the academy, "methods will emerge that are unique to Indigenous Peoples. But we are adaptable. We can use methods that are common to the colonizers research, and adapt these methods to work within our own Indigenous paradigms and methodologies" (Prete, 2019, p. 48).

\section{Methods}

In order to answer the research question, I designed a research project drawing upon the principles of the Beadworking research paradigm and an Indigenous research methodology. Doing so ensured the research project was completed in such a way, as to "fit with and balance my own ways of being and looking at the world" (Weber-Pillwax, 2001, p. 72). To understand and choose the tools needed to compare these two approaches, I drew upon Beadworking's principles of an act of: (a) resiliency and (b) resistance. Beadworking as an act of resistance means to be poised in adaptability and to choose methods that "mesh with the community" (Weber-Pillwax, 2001, p. 168). Thus, methods must be employed that are "the best fit for the communities with which we engage our research with" (Prete, 2019, p. 50). I chose to use surveys, as the research demographic (both Indigenous and non-Indigenous secondary students) are familiar with this format. I adapted the surveys to include the principle of Beadworking as an act of resistance, which is built upon Martin's (2002) privileging the voices of Indigenous Peoples. Thus, I used the surveys in such a way as to return the colonial gaze, that forwards an Indigenous agenda (Prete, 2019).

A survey was administered that was quantitative in nature and used Johnson and Christensen's (2000) 13 principles to construct the survey. The survey consisted of 19 items using a Likert-type scale. The survey was a self-administered paper-and-pencil questionnaire. Self-administered surveys are an ideal choice because they result in greater response accuracy (Braverman \& Slater, 1996). Because of the sensitive nature of the survey (questions in regards to students attitudes toward Indigenous Peoples), maintaining the anonymity of the respondents was more likely to produce honest and accurate answers (Mertens, 2015).

I determined two statistical reliability coefficients to measure the internal consistency of the survey instrument's questions, which ensures the survey data can be considered reliable. In order to demonstrate this, I randomly divided the 19 survey questions into two groups and then calculated correlation coefficients. First, I calculated the section's split-half reliability 
coefficient. Next, I used a Spearman-Brown correction calculation to better estimate the reliability of the survey (Eisinga, te Grotenhuis, \& Pelzer, 2013). The attitude section had a Spearmen-Brown correction value of 0.82. According to Bieger and Gerlach (1996), a reliability coefficient of 0.70 or more is reliable. Therefore, this result indicates a high internal consistency between the questions and the respondents, which means the survey data can be considered reliable.

\section{External validity}

External validity is the degree to which the findings from one study can be applied to other situations (Gall et al., 2003). If researchers can observe the findings from one study in a different situation, the results are considered externally valid (Mertens, 2015). To establish the external validity of this work, I employed the use of a chi-square test. Researchers use chi-square statistics to compare groups on a nominal variable with categorical data (Mertens, 2015). I wanted to determine how similar the study's sample was to the target population. Because I was interested in two populations (Alberta and Canada), I calculated chi-square statistics for both populations.

The Alberta 2011 National Household Statistics and the Canada 2011 National Household Statistics were used. Two chi-squares were calculated for each target population: Alberta and Canada. The first consisted of three categories: (a) the Indigenous and ethnic minority population, (b) the majority population, and (c) the immigrant population. I derived the last chisquare statistics by comparing the ratio of the male to female populations.

The statistical results indicated that the research sample size for female to male ratio was relatively similar to that of Alberta and Canada. However, the sample size differed in terms of ethnicity. The sample size consisted of a higher population of Indigenous and ethnic minorities, and a lower population of immigrants in comparison to Alberta and Canada.

\section{Limitations}

The limitation relates to the population of research participants. This study was limited by the setting in which I conducted the research. The research site was one of the only public high schools in Alberta that offers Aboriginal Studies in the Treaty 7 area. When I conducted a chisquare test to ensure the study's external validity, I discovered a few anomalies between the population of research participants and the Alberta and Canadian population of students. First, Indigenous and ethnic minority students were overrepresented in the population. Second, the representation of immigrant students in the population was lower than expected. It is important that readers keep these anomalies in mind.

\section{Data Analysis}

Beadworking as an act of knowledge transmission relies heavily upon the natural laws of interconnectedness and balance, which speaks to how the Blackfoot People perceive their world through relationships, viewing the world in a holistic way. The bead designs that I create draw upon balance and interconnectedness. My pattern must be geometrically balanced, and the 
pattern and beads will be used in such an interconnected way to reveal relationships amongst one another. I apply this understanding to my analysis of research: "I will analyze the data I have collected and look for patterns that exist within the data...I will determine whether or not a pattern, or relationship, exists between the independent and dependent variables" (Prete, 2019, p. 46).

I began analysis of the questionnaire data by first using the principal-component factor analysis and multivariate analysis of variance (MANOVA) to help me see the patterns that emerge from the data. I wanted to determine which educational approach, either the FNMIPF or Aboriginal Studies 10, made the most significant difference to students' attitudes towards Indigenous Peoples. The named analyses were used to compare the differences between students who had taken FNMIPF or Aboriginal Studies 10.

\section{Principle-component factor analysis}

Principal-component factor analysis was used to identify if any interrelationships existed amongst the 19 items found on the survey. Further, instead of trying to compare 19 items with various variables, I sought patterns among these 19 items, which would enable me to organize them into smaller clusters of items for comparison. In order to do this with minimal loss of data, I used principle-component factor analysis.

In applying the principal-component factor analysis, I observed that 17 of the 19 items correlated a minimum of 0.3 with at least one other item, which suggested reasonable factorability (Neil, 2008). This means there was a pattern found between 17 of the 19 items. Second, the KaiserMeyer-Olkin measure was used to determine the sampling adequacy, which was was 0.76 . This value is above the commonly recommended value of 0.60 (Neil, 2008). Given these overall indicators, I deemed the factorial analysis suitable for all 19 items. Meaning there was a pattern found between all 19 items.

Principle-component factor analysis revealed a levelling off of the Eigenvalues on the scree plot after five factors which explained $59.94 \%$ of the total variance. Based on the recommendations of Hair, Anderson, Tatham, and Black (1998), the correlation cutoff value used in this study is 0.40 as the sample size is larger than 200 respondents. Which means, for a study of this size, I would only need to use a correlation cut off value of 40\%. My principal-component factor analysis levelled off at 59.94\% which indicates a high internal consistency. The point of using principle-component factor analysis was to be able to organize these 19 items into a smaller group of items. The results of the factor analysis placed the 19 items into five factors. After placing the 19 items into the five factors, I named each factor based on the patterns that correlated to each factor. Those factor names are: Factor 1 - perceptions of Aboriginal Peoples; Factor 2 - differences around me; Factor 3 - close Aboriginal relationships; Factor 4 - my differences; and Factor 5 - Aboriginal acquaintances. 


\section{Multivariate analysis of variance (MANOVA)}

I conducted a MANOVA to explore the nature of the relationships between the 5 independent variables and the various group memberships (dependent variable). The five independent variables were the 5 factors that were determined by the principal-component factor analysis (i.e., Factor 1 - perceptions of Aboriginal Peoples; Factor 2 - differences around me; Factor 3 close Aboriginal relationships; Factor 4 - my differences, and; Factor 5 - Aboriginal acquaintances). A MANOVA was used to compare these five factors to the independent variables which are the (a) educational approaches, (b) FNMIPF, and (c) Aboriginal Studies 10. A MANOVA was used to determine if there was a difference between attitudes towards Indigenous Peoples based on which educational approach was employed in their education.

The MANOVA was conducted in two steps. First, the overall hypothesis was tested to determine if any difference existed between the means for the different dependent variables. If the test determined no difference, then regardless of the educational approach, students would have the same attitude towards Indigenous Peoples. Second, if the first test was significant, a follow up test would be conducted to explain the differences between the dependent variables (Bray \& Maxwell, 1985). In other words, if a difference did exist between the two educational approaches, we would want to know which of the five factors they differed on. A post-hoc test would be needed to determine this.

\section{Findings}

I first tested to determine whether enrolment in Aboriginal Studies 10 made a difference in the perception of Indigenous Peoples. I grouped the students into those who took Aboriginal Studies and those who had not taken Aboriginal Studies. I conducted a MANOVA to explore the relationships among the five factors and the two groups. The following is the group membership and size, namely, respondents who: (a) did not take Aboriginal Studies $10(\mathrm{n}=181)$; and (b) who did take Aboriginal Studies $10(\mathrm{n}=36)$.

The MANOVA revealed a significant multivariate main effect whether the students took Aboriginal Studies 10 or not: Pillai's Trace $=0.233, \mathrm{~F}(5,211)=12.846, \mathrm{p}<.001$; thus a substantive relationship exists between the students who took Aboriginal Studies 10 and their perceptions of Aboriginal Peoples. Levene's test of equality of error variance was conducted using a cutoff value of 0.05 (Bross, 1971). The test revealed that the $\mathrm{p}$ values for Factor 1 (perceptions of Aboriginal Peoples) and Factor 4 (my differences) were less than 0.05, which means that these factors violated the homogeneity of variances assumption. To determine the factors that differed, I conducted a univariate ANOVA. Results show significance values in Factor 1 (perceptions of Aboriginal Peoples; $p=0.00$, partial $\eta 2=0.278$ ), Factor 3 (close Aboriginal relationships; $\mathrm{p}=0.00$, partial $\eta 2=0.115$ ), and Factor 4 (my differences; $\mathrm{p}=0.00$, partial $\eta 2=0.143$ ). Thus, Factors 1,3 , and 4 were significantly different between students who had and those who had not taken Aboriginal Studies 10. 
I used discriminant analysis to conduct a MANOVA test of the hypothesis of whether Aboriginal Studies 10 affects student perceptions of Aboriginal People on a linear combination of the five variables (perceptions of Aboriginal Peoples, differences around me, close Aboriginal relationships, my differences, and Aboriginal acquaintances). The overall chi-square test was significant $($ Wilks $\lambda=.767$, chi-square $=56.470, \mathrm{df}=5$, canonical correlation $=.483, \mathrm{p}<0.001$; Figures 26 and 27). Function 1 explained $100 \%$ of the variance of the analysis. The discriminant function combined variable equation is $\hat{y}=.841 * \mathrm{f} 1+.088 * \mathrm{f} 2+.148 * \mathrm{f} 3+.435 * \mathrm{f} 4-.269 * \mathrm{f} 5$. The structural coefficients revealed that the correlating factors, in descending order, for function 1 are: perceptions of Aboriginal Peoples, my differences, close Aboriginal relationships, Aboriginal acquaintances, and differences around me (Figure 1). These findings will be discussed further in the discussion section. Factor 2 (differences around me) is negatively correlated and does not contribute to differences among the ethnic groups in this study. The discriminant analysis revealed that the two groups in this study (students who had taken Aboriginal Studies 10 and those who had not taken Aboriginal Studies 10) differ on four factors (perceptions of Aboriginal Peoples, my differences, close Aboriginal relationships, and Aboriginal acquaintances).

\begin{tabular}{l|c|}
\hline & Function \\
\hline $\begin{array}{l}\text { Perceptions of Aboriginal } \\
\text { Peoples }\end{array}$ & 1 \\
\hline $\begin{array}{l}\text { My differences } \\
\text { Close Aboriginal }\end{array}$ & 0.828 \\
\hline Aboriginal acquaintances & 0.508 \\
\hline Differences around me & 0.194 \\
\hline
\end{tabular}

Figure 1. Structure matrix. coefficients.

\section{Discussion and Conclusions}

The colonization has had a lasting negative affect upon the lives of the Indigenous Peoples of Canada. Education has largely played a role in the colonization of, and attempts at assimilating, Indigenous Peoples (Truth and Reconciliation Commission of Canada, 2015; National Centre for Truth and Reconciliation, 2019). Senator Murray Sinclair suggests that education will be a means to reverse these negative implications (National Centre for Truth and Reconciliation, 2019). Thus, this study sought to explore how education can be used to help foster positive attitudes towards the Indigenous Peoples of Canada. As a member of the Kainaiwa Nation, located in Alberta, Canada, I focused this research study on what Alberta Education can do as part of their secondary education program to rectify this problem. A quantitive study grounded in a Beadworking research paradigm and an Indigenous research methodology was used to answer the research question: "How does engaging with either the First Nations, Metis, and Inuit policy 
framework or Aboriginal Studies 10 course work affect students' attitudes towards Indigenous Peoples?"

A quantitative survey was used to compare students who had been educated using the FNMIPF to students educated in Aboriginal Studies 10. Data analyses included principal-component factor analysis, MANOVA, and univariate ANOVA. Principal-component factor analysis was used to reduce the 19 questions on the survey down to 5 themes, called factors. This was done to simplify the comparison of the 19 questions between students who had taken Aboriginal Studies 10 and those students who had not. The MANOVA results indicated that a statistical significance existed between the way students who took Aboriginal Studies 10 answered the survey questions, to those students who had not taken Aboriginal Studies 10. Univariate ANOVA was used to determine which of the five themes students differed on, based on whether they had taken Aboriginal Studies. The univariate ANOVA results showed that students differed on four of the five factors (perceptions of Aboriginal Peoples, my differences, close Aboriginal relationships, and Aboriginal acquaintances), while Factor 2 (differences around me) was not a statistically significant difference between the two groups of students.

Factor 1 (perceptions of Aboriginal Peoples) had the largest discrepancy between the two groups of students. Students who enrolled in or who had taken Aboriginal Studies 10,had a more positive view of Indigenous Peoples in terms of the following: they liked learning about Aboriginal People in the school, liked having Aboriginal students in their class, felt that Aboriginal People are an important part of Canadian history, felt that Aboriginal People are an important part of Canadian society, and felt that Aboriginal People are contributing members of society. On the other hand, students who had not taken Aboriginal Studies 10 did not hold those same opinions regarding Indigenous Peoples.

Factor 4 (my differences) had the second largest discrepancy between the students who had taken Aboriginal Studies compared to those who had not. Students in both groups answered differently for how often they felt uncomfortable in their school according to the following four items: ethnicity, culture, skin colour, and accent. Factor 3 (close Aboriginal relationships) had the third largest discrepancy between the two groups of students. Students who enrolled in or who had taken Aboriginal Studies 10 felt more comfortable with the following statements than those students who had not taken Aboriginal Studies: dating an Aboriginal person, having Aboriginal friends, or if their friend was dating an Aboriginal person.

Factor 5 (Aboriginal acquaintances) was the fourth largest discrepancy between the two groups of students. Students who had taken or who were enrolled in Aboriginal Studies 10 were more comfortable with the following statements compared with those who had not taken Aboriginal Studies 10: having an Aboriginal person as a next door neighbor, and working with someone who is an Aboriginal person. As well, those who had taken or who were enrolled in Aboriginal Studies 10 more likely felt that racism existed in the school, compared to those who had not taken Aboriginal Studies 10. 
The statistical analyses suggest students who were enrolled in, or had taken Aboriginal Studies 10, had a more positive view of the Indigenous Peoples of Canada. Conversely, students educated only using the FNMIPF had a more negative view of Indigenous Peoples. Several reasons may have contributed to these findings, which are: the FNMIPF is a token gesture, and the policy framework has not been implemented in the schools where the participants were educated (Zurzolo, 2006); the Indigenous perspectives that had been integrated into the curriculum was not authentic Indigenous knowledge but rather reinforced negative perceptions and stereotypes of Indigenous Peoples (Banks, 1989); teachers were not prepared to teach Indigenous content and thus did not include Indigenous perspectives in their classrooms (Kanu, 2005; Wiens, 2012); the content may have been present, but the students' interest in learning Indigenous perspectives was waning (Blood, 2010); the pedagogical approach used in the classroom was not conducive to teaching Indigenous knowledge systems (Banks, 1989); or, perhaps the FNMIPF is ineffective and should be revised and rewritten.

These results also indicate that students entered high school with already negative preconceived ideas about Indigenous Peoples. Thus, the high school becomes the very last attempt at changing students' perceptions of Indigenous Peoples before students enter into adulthood. In light of this, I make the following recommendations for future policy and research.

\section{Recommendations for future policy}

1. The MANOVA results indicate Aboriginal Studies 10 made differences to the students' perceptions of Indigenous Peoples. Aboriginal Studies 10 is an optional course that students can take at the secondary level in Alberta Education schools. However, this course is not offered in every Alberta Education school. While it is tempting to recommend that students must take a mandatory Aboriginal Studies 10, or an equivalent course to graduate from high school, it is possible for students to still enter post-secondary institutions without taking all of the required courses for a high school diploma. Thus, to ensure that students receive the Aboriginal Studies 10 curriculum during their education, I recommend that the Aboriginal Studies 10 curriculum be joined with the Social Studies curriculum. Social Studies 9 through 12 will be dispersed with units from the Aboriginal Studies 10 course. Professional development already exists for the Social Studies curriculum and can be adjusted to include Aboriginal Studies 10 units.

2. The MANOVA results also indicate that the First Nations, Metis, and Inuit policy framework (FNMIPF) was ineffective at the school where this research took place. This may indicate that the school was not enforcing the policy framework, or teachers were not integrating Indigenous perspectives. Thus, I recommend that Alberta Education either enforce the mandatory integration of Indigenous perspectives into their kindergarten to grade 12 curriculum, or re-write and update the FNMIPF. 


\section{Recommendations for future research}

1. I recommend that this research study be replicated using a stratified random selection approach to ensure more schools offering Aboriginal Studies are included.

2. I recommend that a future research study be conducted to determine which approach is used in the classroom when it comes to teaching Indigenous knowledge and perspectives, according to the four approaches outlined by Banks (1989). Which of Banks' approaches is most used in classrooms that integrate Indigenous perspectives into the mainstream curriculum? Which of Banks' approaches is most used in the Aboriginal Studies 10 course?

\section{Acknowledgements}

I would like to acknowledge and give thanks to the superintendent and school principal who approved this research. As well, give thanks to the students who participated in the study. I would also like to give thanks to my Ninn'naa Dr. José da Costa, for teaching and mentoring me in quantitative analyses.

\section{References}

Aboriginal Affairs and Northern Development. (2011). A history of Indian and Northern Affairs Canada. https://www.aadnc-aandc.gc.ca/eng/1314977281262 /1314977321448

Alberta Education. (1987). Policy statement on Native education in Alberta. http://education.alberta.ca/teachers/fnmi/fnmipolicy/policyresults.aspx

Alberta Education. (2002). First Nations, Métis, and Inuit education policy framework. http://education.alberta.ca/teachers/fnmi/fnmipolicy.aspx

Alberta Education. (2004). First Nations, Métis, and Inuit education policy framework: 2004 progress report. http://education.alberta.ca/media/164120/fnmi2004.pdf

Alberta Education. (2008). First Nations, Métis, and Inuit education policy framework: 2008 progress report. http://education.alberta.ca/media/840103/fnmi\%20progress\%20report $\% 202008 \% 20$ final.pdf

Amir, R. (2018). Cultural genocide in Canada? It did happen here. Aboriginal Policy Studies, 7(1), 103-126. DOI:10.5663/aps.v7i1.28804

Bagot, R. (1842). Report on the affairs of the Indians in Canada. Retrieved from http://projectofheart.ca/historical-documents/

Banks, J. A. (1989). Multicultural education: Issues and perspectives. Allyn and Bacon.

Bastien, B. (2004). Blackfoot ways of knowing: The worldview of the Siksikaitsitapi. University of Calgary Press.

Bieger, G. R., \& Gerlach, G. J. (1996). Educational research: A practical approach. Delmar.

Blood, T. L. (2010). Integrating an Aboriginal perspective: Issues and challenges faced by nonAboriginal biology teachers [Unpublished master's thesis]. University of Alberta.

Bonds, A., \& Inwood, J. (2016). Beyond white privilege: Geographies of white supremacy and settler colonialism. Progress in Human Geography, 40(6), 715-733. DOI: $10.1177 / 0309132515613166$

Braverman, M. T., \& Slater, J. K. (1996). Advances in Survey Research. New directions for evaluation, 70, 1-104.

Bray, J. H., \& Maxwell, S. E. (1985). Multivariate analysis of variance. Sage Publications. 
British North American Act. (1867).

https://www.legislation.gov.uk/ukpga/1867/3/pdfs/ukpga_18670003_en.pdf

Bross, I. D. J. (1971). Critical levels, statistical language and scientific inference. In V. P.

Godambe \& D. Sprott (Eds.), Foundations of statistical inference (pp. 500-513). Holt, Rinehart \& Winston of Canada.

Bryce, P. H. (1907). The story of a national crime, being an appeal for justice to the Indians of Canada.

http://www.archive.org/stream/storyofnationalc00brycuoft/storyofnationalc00brycuoft_dj vu.txt

Canadian Encyclopedia Online. (2009). Indian Act. http://www.thecanadianencyclopedia.com/index.cfm?PgNm=TCEParams $=$ A1ARTA0003975

Carney, R. (1995). Aboriginal residential schools before confederation: The early experience. Historical Studies, 61(1), 13-40.

Eisinga, R., te Grotenhuis, M., \& Pelzer, B. (2013). The reliability of a two-item scale: Pearson, Cronbach or Spearman-Brown? International Journal of Public Health, 58(4), 637-642.

Fredrickson, G. M. (1982). White supremacy: A comparative study of American and South African history. OUP USA.

Gall, M. D., Gall, J. P., \& Borg, W. R. (2003). Educational research: An introduction (7 $7^{\text {th }}$ ed.). Allyn and Bacon.

Gradual Civilization Act. (1857). http://caid.ca/GraCivAct1857.pdf

Hair, J. F., Anderson, R. E., Tatham, R. L., \& Black, W. C. (1998). Multivariate data analysis (5th ed.). Prentice Hall.

Indian Act. (1876). http://epe.lacbac.gc.ca/100/205/301/ic/cdc/aboriginaldocs/stat/html/1876ap12.htm

Indian Act. (1884). http://epe.lac-bac.gc.ca/100/205/301/ic/cdc/aboriginaldocs/m-stat.htm Indian Act. (1894). https://epe.lacbac.gc.ca/100/205/301/ic/cdc/aboriginaldocs/stat/pdf/Ia1894.pdf

Indian Act. (1895). Retrieved from http://epe.lacbac.gc.ca/100/205/301/ic/cdc/aboriginaldocs/stat/html/IA1895.htm

Indian Act. (1914). http://epe.lacbac.gc.ca/100/205/301/ic/cdc/aboriginaldocs/stat/html/IA1914.htm

Indian Act. (1920). http://epe.lacbac.gc.ca/100/205/301/ic/cdc/aboriginaldocs/stat/html/1920j101.htm

Indian Act. (1927). http://epe.lacbac.gc.ca/100/205/301/ic/cdc/aboriginaldocs/stat/html/1927mr31.htm

Indian Act. (1985). https://laws-lois.justice.gc.ca/eng/acts/i-5/

Johnson, R. B. \& Christensen, L. B. (2000). Educational research: Quantitative and qualitative approaches. Allyn \& Bacon.

Kanu, Y. (2005). Teachers' perceptions of the integration of aboriginal culture into the high school curriculum. The Alberta Journal of Educational Research, 51(1), 50-68.

Kirkness, V. J. (1999). Aboriginal education in Canada: A retrospective and a prospective. Journal of American Indian Education, 39(1), 14-30. 
Mako, S. (2012). Cultural genocide and key international instruments: Framing the indigenous experience. International Journal on Minority and Group Rights, 19(2), 175-194. DOI $10.1163 / 157181112$ X639078

Martin, K. (2002). Ways of knowing, ways of being, and ways of doing: Developing a theoretical framework and methods for Indigenous re-search and Indigenist research. Unpublished manuscript.

Mertens, D. M. (2015). Research and evaluation in education and psychology: Integrating diversity with quantitative, qualitative, and mixed methods ( $4^{\text {th }}$ ed.). Sage.

National Centre for Truth and Reconciliation. (7, February 2019). TRC Mini Documentary Senator Murray Sinclair on Reconciliation [Video]. Youtube. https://www.youtube.com/watch?v=wjx2zDvyzsU

Neil, J. (2008). Writing up a factor analysis. http://www.bwgriffin.com/gsu/courses/edur9131/content/Neill2008_WritingUpAFactorA nalysis.pdf

Pratt, R. H. (1973). The advantages of mingling Indians with Whites. In F. P. Prucha (Ed.), Americanizing the American Indians: Writings by the "friends of the Indian" 1880-1900 (pp. 260-271). Harvard University Press.

Prete,T. (2019). Beadworking as an Indigenous Research Paradigm. Art/Research International: A Transdisciplinary Journal, 4(1), 28-57. http://dx.doi.org/10.18432/ari29419

Rabaka, R. (2007). The souls of white folk: WEB Du Bois's critique of white supremacy and contributions to critical white studies. Journal of African American Studies, 11(1), 1-15. DOI 10.1007/s 12111-007-9011-8

Reyhner, J., \& Singh, N. K. (2010). Cultural genocide in Australia, Canada, New Zealand, and the United States. Indigenous Policy Journal, 21(4), 1-26.

Royal Proclamation. (1763). https://www.sfu.ca/ palys/The\%20Royal\%20Proclamation.pdf

Ryerson, E. (1898). Statistics respecting Indian schools with Dr. Ryerson's report of 1847, Appendix A. Government Printing Bureau.

Scheffel, D. Z. (2000). The post-anthropological Indian: Canada's new images of Aboriginality in the age of repossession. Anthropologica, 42(2), 175-187.

Treaty 7 First Nations Education System. (2000). Native education policy review. http://education.alberta.ca/media/164162/treaty7.pdf

Truth and Reconciliation Commission of Canada. (2015). Truth and Reconciliation Commission of Canada: Calls to action. http://www.trc.ca/websites/trcinstitution/File /2015/Findings/Calls_to_Action_English2.pdf

Walter, M. (2005). Using the 'power of the data' within Indigenous research practice. Australian Aboriginal Studies, 2, 27-34.

Weber-Pillwax, C. (2001). What is Indigenous research? Canadian Journal of Native Education, 25(2), 166-176. https://journalhosting.ucalgary.ca/index.php/jet/article/view/52552

Wiens, R. (2012). On integrating Aboriginal perspectives: The perceptions of Grade 10 English language arts teachers in a large urban school division in Western Canada. [Unpublished master's thesis, University of Manitoba].

Yellow Bird, M. (2004). Cowboys and Indians: Toys of genocide, icons of American colonialism. Wicazo Sa Review, 19(2), 33-48. http://www.jstor.org.login.ezproxy.library.ualberta.ca/stable/1409497 
Zurzolo, C. (2006). An exploration of the experiences of non-Aboriginal teachers integrating Aboriginal perspectives into the Manitoba social studies curriculum. [Unpublished master's thesis, University of Manitoba]. 